Journal of Humanities and Social Sciences Studies (JHSSS)

ISSN: 2663-7197

DOI: 10.32996/jhsss

Journal Homepage: www.al-kindipublisher.com/index.php/jhsss

\title{
An Analysis of the Socio-legal Framework Around Objectification of Women in India
}

Bhavya Gupta

Student, Montfort Senior Secondary School, Ashok Vihar, New Delhi, India

Corresponding Author: Bhavya Gupta, E-mail: ritubhavya62240@gmail.com

\author{
ARTICLE INFORMATION \\ Received: December 02, 2020 \\ Accepted: January 05, 2021 \\ Volume: 3 \\ Issue: 1 \\ DOI: 10.32996/jhsss.2021.3.1.2
}

\section{KEYWORDS}

Objectification, cross cultural analysis, Indian Penal Code, Indecent Representation of Women's Act, Women issues in India

\section{ABSTRACT}

Objectification is the act of treating a person solely as an object of sexual desire. Sexual objectification is one of the biggest reasons why we live in a world flooded with sexualized images of women who are presented to be immaculate goddesses, which every girl aspires to emulate leading to mental health issues, loss of selfesteem, exploitation and harassment. Sexual objectification constitutes of two dimensions within itself, firstly, treating women as mere objects and secondly, dehumanizing, i.e. when women are considered to be mindless entities and their internal virtues are completely forgotten about. The current legal frameworks around the world take a limited view of the problem and deal with certain aspects of the problem while ignoring others. This study tries to holistically analyse the problems from a victim standpoint and does a cross cultural analysis with a special focus on laws in India and a brief overview about the laws in other countries like Belgium, France, Finland, Greece, Norway, South Africa, Spain, United States of America, United Kingdom, Nicaragua to identify areas where the legal frameworks need to be strengthened in order to prevent women from being objectified. It was noticed that most of these countries did not have a peculiar law against objectification. However, most of the western countries focus on protecting women against gender stereotypes in advertisements. This was also followed by a 22pointer gap analysis on the Indian existing laws. Furthermore, the primary research encompassed a deliberation with a panel of socio-legal experts, whose ideas and suggestions have in turn been included in the paper. The research paper ends with recommendations which were devised after a lot of brainstorming.

\section{Introduction}

Objectification can be defined as to when there is singling out of any of the body parts or even the entire body and are just used as a contraption to consummate their desires. Incessant objectification, which may include gaze, sexually coloured and condescending remarks, humour etc. can have both, negative and positive effects on a woman's emotional being. However, there is usually an adverse effect as it leads to continuous self-monitoring by women, i.e. Self-objectification. Women tend to spend a greater period of their day scrutinizing their appearance, which in turn leaves them with very little energy to focus on their developmental goals (education, job etc.). Furthermore, from the literature review, it is noted that most of the objectification theorists and researchers have studied this topic from a psychological point of view but this research gives a legal perspective as well as a social perspective pertinent to the above issue.

Thus, we can conclude, sexual objectification is one of the biggest reasons why we live in a world flooded with sexualized images of women who are presented to be immaculate goddesses, which every girl facsimile. Sexual objectification constitutes of two dimensions within itself, firstly, treating women as mere objects and secondly, dehumanizing, i.e. when women are considered to be mindless entities and their internal virtues are completely forgotten about. They are constantly reminded how they are only use is to fulfil a man's sexual desires. India lags no behind among all the other countries wherein women are objectified. In India

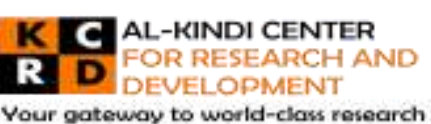

Your gateway to world-class research

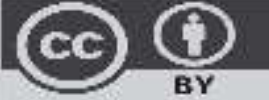

Published by Al-Kindi Center for Research and Development. Copyright (c) the author(s). This open access article is distributed under a Creative Commons Attribution (CC-BY) 4.0 license 
too objectification can be witnessed from Bollywood, advertisements, social media sites, newspapers, to eve-teasing and catcalling. However, India reports robustly a low rate of self- objectification as compared to other countries such as USA, Australia, UK etc.

The social media sites such as Instagram, also is a key factor in aggrandizing self- surveillance and self-objectification among women. The general trend displays that the social media sites promote themes and ideas which commodify and objectify women. For instance, social media can be used by men to monitor attractive female celebrities or boys trying to monitor their female peers, combined with exposure to extremely sexualised media. However, social media can also be used for selfconstruction of identity by women. According to the opinion of the author of this research paper, the intention with which a person posts picture on their social media handle also brings about a lot of difference, it can either bring about a positive or a negative change. For instance, if a girl posts a picture keeping in mind the way she looks, wears revealing clothes or edits the picture using various apps, with the intention that if it would be liked by other boys, then she is bringing herself to be objectified by people. Alternatively, if the same picture is posted by her, but this time the thought she has in the back of the mind is that posting the picture makes her happy and feel confident, then this will have a positive impact on her and even if objectified, it would bring no difference to her. Today, even the entertainment industry is creating a stereotype for the young generation and is creating a very incompatible view of beauty, which is quite detrimental for the society.

The view that everything cannot be viewed as objectification, but as the basic human nature has also been advocated by several students. While being attracted to someone is the basic nature of a human being. However, just being attracted to the person because of his/her physical appearance is erroneous.

Objectification is not a new concept but has been evolved over time. So, we will be studying the viewpoints of significant scholars.

\subsection{Objectification Theories}

Martha Nussbaum basically believes that people usually have a very facile understanding of objectification. She, therefore has tried to give seven different dimensions to it. In her view the topic of objectification is paramount to the concept of the Marxist view on capitalism and slavery. Furthermore, the out-turn of objectification is not necessarily negative, but can be taken in a positive spirit as well in some circumstances. Instrumentality, denial of autonomy, inertness, fungibility, violability, ownership, denial of subjectivity are the seven ways in which a person can be objectified. According to Nussbaum, there can be several other dimensions apart from these seven which can objectify a person. Instrumentality basically means treating something or someone in a way they actually should not be treated (like treating a human as an object). It is considered to be the most troublesome out of the seven. Under the scope of instrumentalization, the way women are 'seen', apart from the way they are 'treated' also plays a great role. An example of positive objectification, according to her can be 'Lawrentian Objectification'. (Nussbaum, 1995)

Reduction to body means just focusing on the physical body parts of the women and forgetting about her internal virtues. Lastly, silencing a person means not being attentive to the way how their counterpart is feeling and considering that the person lacks the ability to speak. These are the three more properties that have been proposed by Langton to be added to Nussbaum's list. (Langton 2009). Rae Langton too discusses that there can be an attainable relatedness between the consumption of pornography and objectification. Rae Langton writes: "As a matter of human psychology, when men sexually use objects, pornographic artifacts, as women, they tend to use real woman as objects. One weaker variant of this causal claim might be restricted to a subset of pornography... As a matter of human psychology, when men sexually use objects as women, and those objects are pornographic artifacts, whose content is violent or misogynistic, then they will tend to use real women as objects" (Langton 1995, 178). Langton further highlights the difference between 'objectivity' and 'objectification'. According to him, objectivity refers to our beliefs and how they are arranged and can fit in this world, which are in turn in the right direction. In contrast to this, objectification refers to the way the world complies with our beliefs i.e. an objectifier always attempts to arrange the world based on his desires, which in turn is in the wrong direction. (Langton 2000, 138-142)

Immanuel Kant believes that sexual objectification is an attribute of sexuality because sexual desire is so substantial and intoxicant that it would necessarily involve objectification. This is because under sexual desire, one almost loses control over oneself and hence no more cares about the way the other person feels and hence treats the person as a mere commodity. Immanuel Kant compares the objectification a person to the use of a lemon. Just like a lemon is used by an individual, after which it is repudiated. (Kant Lectures on Ethics, 163 and 165). The way out from sexual objectification proposed by him lies in the institution of marriage.

Catherine Mackinnon and Andrea Dworkin, who are anti-pornography feminists strongly link inequality faced by women to objectification and contradict Immanuel Kant's theory on objectification by arguing that the objectification of men and women 
are lopsided. According to them, the objectifier is always the more powerful one as compared to the victim who is weak. This means that since the power shared by men and women are disparate, the way each of them express their sexuality is quite different. Sexual expression by men is way more ascendant the way a woman expresses her sexuality, which is in turn in a more submissive manner and are usually prone to self- objectification. Furthermore, the consumption of pornography by men is another major reason for the objectification of women, which in turn is tightly linked to gender inequality. MacKinnon defines pornography as "the graphic sexually explicit subordination of women through pictures or words that also includes women dehumanized as sexual objects, things, or commodities; enjoying pain or humiliation or rape; being tied up, cut up, mutilated, bruised, or physically hurt; in postures of sexual submission or servility or display; reduced to body parts, penetrated by objects or animals, or presented in scenarios of degradation, injury, torture; shown as filthy or inferior; bleeding, bruised, or hurt in a context that makes these conditions sexual" (MacKinnon 1987, 176). MacKinnon further argues that the consent of the women of her being used as an instrument for fulfilling man's sexual desires is not enough. For example- a woman enters into the profession of prostitution because of lack of options. MacKinnon writes: "The sex is not chosen for the sex. Money is the medium of force and provides the cover of consent" (MacKinnon 1993, 28).

Barbara L. Fredrickson and Tomi-Ann Roberts have accurately elucidated on objectification in their objectification theory (1997). Objectification theory proposes that over time people, usually men have learn to internalize women by their physical self/body. Sexual objectification itself is an umbrella term which encompasses several kinds of gender oppress ions. Furthermore, response to sexual objectification is not the same. It differs with respect to age, class, gender, sexuality, and other physical and personal attributes. Karen Horney indicated the "socially sanctioned right of all males to sexualize all females, regardless of age and status." Objectification may variate from using sexual violence against a women to assess someone based on their physical appearance and can spread out to three areas, I) interpersonal and social encounters, II) visual media depicting interpersonal and social encounters, III) visual media that singles out body and body parts of women. Ex.- pornography, main stream films, television, advertisements, women magazines, sports photography (Fredrickson, Roberts, 1997).

The antecedent conditions or the ideological factors, such as patriarchy, gender based justification, sexism leading to objectification, are being internalized by men and women, both and hence becoming highly normalized. Face-ism is the ratio where the distance from the apex of the head of a person to lowest visible point of chin is the numerator and the distance from the top of the head to the lowest visible part of the individual's body is the denominator. Archer along with Iritani, Kimes and Barrios found out that men in contrast to women tend to have more facial prominence various visual representations, which they termed as face-ism. This was done by conducting 5 studies more than 30 years ago (Archer, 1983).

It has been indicated by the above theories that the topic of objectification is multi-dimensional and therefore eminent theorists over the time have formed various contradictory perspectives and has broadened the scope of this topic. Now, we will have study about the flow of this research paper.

\subsection{Structure of the Paper}

The idea of the paper is to explore the various facets of objectification, by understanding the work that has been done till date across the world. It has been prevalent in most parts of the world along with India. This is followed by a survey of literature in India as well as abroad, which is in turn a way to find out what research has been done about the topic and the major theories around objectification, along with the study of current Indian legal system. Based on discussions and deliberations by significant scholars and what is actually there in the law, gaps will be identified. The next step comprises of talking to eminent lawyers and taking their recommendations and legal opinion. The research paper also focuses on studying laws in various countries to do a comparative analysis, which would be followed by an analysis of whether these laws are suitable enough to be adopted in India and if we can acquire something from these. Lastly, recommendations will be given at the end by studying the various international laws and taking the guidance of some lawyers on how the legal framework around objectification can be improved in India.

\section{Literature Review}

Having studied about some of the pathbreaking objectification theories in the previous section, we will focus on some of the work done by eminent scholars in the area of objectification of women, in order to better understand the body of knowledge that already exists in the area.

According to Sarah J. Gervais et al. (2019), it is the interaction process between two people which plays a key role in objectifying women, which in turn has been seldom researched or considered by people. Therefore, she has advanced the Social Model of Interaction (SIMO). SIMO advocates that objectification of women has stemmed through the sexual goals between men and women. The various areas that SIMO encompasses are - objectifying interaction processes, why objectification is assessed as to be worthwhile. She concludes by saying that one way to eliminate such wrong practices and gender inequality, more male allies 
need to take a stand to support this issue. Therefore, we need an experimental and strapping scale which might enable each one of us to recognize how men can contribute in acknowledging gender equality.

Stephanie E Davis (2018) advocates that the building of one's identity is highly influenced by the usage of social media. The domination can be on identity, sexuality, and gender. The erroneous and prejudice themes which are reinforced on these social media sites are quite troublesome. Stephanie has, through the paper has scrutinized two Instagram sites which precisely earmark individuals who are college aged. The basic idea behind these sites, which have several followers, is to signify the college experience of various followers. However, it has been established through this research that objectification of female students of college, who are shown submissive to their male counterparts, along with being subjected to physical and sexual aggression and masculinity becoming a matter of pride (being encouraged) at the expense of are few problematic themes quite evident through these websites. There is also emphasis on a young and white college experience.

According to Elise Holland et al. (2016) quite scarce research has been done which scrutinizes how the objectification has an impact on the psychology of as women and what is its pervasiveness. For this, they recorded the incidence of objectification during a period of one $(\mathrm{N}=81)$. It was reported by the participants that the most common way of them being sexually objectified was through gaze and experienced sexual objectification 1.35 times every day. They were picked out every 2 days on an average. Quite less work has been done in considering the impact that objectification has on women and its occurrence, in face of the fact that women in western societies face regular. Hence, the study of this issue was also of paramount importance in this research.

Dax J. Kellie et al. (2019) advocates that people often consider women who are shown to be sexualised as lacking of other attributes like mental abilities or good personality or moral status. Therefore, his two studies assess how the appearance of a woman effect in her being objectified. Through these studies, it was found out that there is a robust link between women being objectified and their appearance. Furthermore, it was seen that women were dehumanised, the ones who are more open to casual sex.

Dawn M. Szymanski et al. (2011) has through his research paper has tried to make us understand that how the Objectification theory plays a key role in us acknowledging and arbitrating the way a woman's life can be ameliorated in context where the female bodies go through sexual objectification. The objectification theory has also been extended to woman's substance use and abuse and how a sexually objectifying environment forefronts sexual objectification.

Stephanie V. Ng, through her article has suggested why recognizing the impact of social media and sexualization of adolescent girls must of importance to psychiatrist and mental health workers. She tells how the old age pressures on adolescent girls to conform to certain sexual narratives has become even more intensified in this age of social media. It has also been suggested that though it is not uncommon for girls to be appreciated (usually by males having objectifying intention), it has also been noticed how they are labeled erroneously. Thus, she concludes by saying that there is a need of awareness and social media literacy among both genders.

Nancy Bauer holds has expressed her thoughts on self-objectification by females and how the recent occurrences of female college students claiming to gain pleasure on being objectified and by turning herself into a commodity of the desire of a boy and the boys in turn incident with pride and the sense of being powerful (Bauer 2011, 124). Thus, Bauer concludes that in order to objectification being stopped, a very pivotal step is not men stop objectifying women, but also that "women care about abjuring the temptation to objectify themselves" (Bauer 2011, 128).

Several feminists share the perturb regarding the ceasing of objectification which is accompanied with the outer appearance of a woman. However, Janet Richards advocates that the engrossment in one's appearance is a matter of subjectivity rather than being a feminist matter (Richards 1980, 184-204). Even Natasha Walter claims that if a woman is engaged or too obsessed about the way she is looking, then even that cannot be equated to complete objectification. According to her, even men in our society seek to be admired and engage in self decoration. (Walter 1998, 86-102).

\subsection{Objectification in Indian context}

According to Sunayan Bhattacharjee (2019) the mainstream English newspapers in India are blameworthy of objectifying the female form and thus through this research paper he has attempted an investigation by analysing a small-scale sample of the pictorial coverage of women by the four major pan-Indian English language dailies, to see the portrayal of female body. The analysis proves that the extensive display of female body in print is not exactly a concerted effort orchestrated by all well-known publications to objectify female body, but the up to the minute content policies can be inculpated, which are followed by The Times of India and Hindustan Times. It can be very well concluded that both these newspapers have stretched female content in their respective print sections to an obscene extent which have a very restricted association with the content being presented. Thus, we experience an intensification of visually provocative material in some of the pan-Indian English language newspapers. 
The research paper by Ishdeep Kaur Bhandari (2018), proposes that barely any research has been done on the commodification of women in television advertisements, serials, magazines and movies and how the repercussions of such commodification include increase in the rate of cosmetic surgeries, eating disorders and its effect on a woman's self-image. This also affects the attitudes of the viewers and society towards women. This is an Indian women focused research. It is not uncommon for the women being treated as objects and hence being referred to as 'creatures'. To put it in simple terms, a woman is used as a product that is selling another product.

The current investigation by Zahabia Z. Slatewala (2019) makes an important contribution to the relevant literature regarding how women in Indian rap and item songs are in an unpalatable manner are objectified. One major goal of the study also includes to measure differences between visual and behavioural sexual objectification based on the objectification theory. Inspecting the varying pattern of objectification over the years was a main part of the study. The results suggest that objectification based on behaviour of women is less as compared to the objectification based on appearance(visual objectification).

Through this research paper, Miss Ritu Atulbhai Gor (2018) has tries to express her concern on about how media, be it movies, music videos or television play a detrimental role in portraying women as sexual objects rather than women. In conclusion, it has been said that it is essential we must stop creating typecasts because this can surely lead to detrimental practices which can harm the society.

Shachi Irde, in her article ${ }^{2}$ has indicated how women in India even at their workplace are barbarously objectified and the intensity with which it is ingrained in the Indian society. She has also expressed how in an arranged marriage in India, it is the expectation of the groom and the in-laws from the female to achieve the 'social standards'. She advocates that the workplace for a woman must keep in mind the possible predicaments a woman can face and thus make sure of a prudent environment.

Hence, we have studied that how objectification of women has been prevalent since a long period of time. We also witnessed how objectification of female body in India is mainly prevalent in media (especially item songs and advertisements). Now, in the next section we will be studying the existing Indian as well as International laws that exist for the objectification of women.

\section{India Legal Perspectives}

3.1 The indecent representation of women (prohibition) act, 1986 act no. 60 of 1986

This act intends to forbid the indecent representation through any manner, such as publications or advertisements, writings, paintings and figures. According to the act, the 'indecent representation' has been defined woman's body, any body part or even her form being represented in such a way that it is considered to be salacious or derogatory.

Further, section 3 and section 4 of this act prohibits anyone from taking part in the broadcasting or display of advertisements and to supply, disseminate, post etc. any visual representation or writing or figure in any form that objectifies women through representing her indecently.

which contains indecent representation of women in any form, respectively. Section 5 of this act authorizes any Gazetted officer (state government) has the right to forage at any point in time and any place, where they consider any crime has been committed under this act. However, for entry in a private dwelling a warrant is required. They also have the power to seize anything that is believed to be an indecent representation of women and examine any records that can be used as an evidence which in turn can be used to prove that a transgression has been perpetrated.

If a person infringes the provisions of section 3 and 4, on the first conviction would be liable to imprisonment of both a term which may extend to two years and a fine which can extend to two thousand rupees. On the subsequent conviction, the imprisonment would be no less than six months and may extend to five years, along with a fine not less than ten thousand rupees and can extend to one lakh rupees. However, any offence committed under this act is bailable and cognizable (section 8 ). Section 10 of this act states that the central government has the power to make laws with the approval of both the houses of the parliament on the matter of the way the seizure needs to take place or how shall the seizure list would be prepared or any other matter which is required without any prejudice to the pre-existing provisions of this act for the further implementation of the provisions under this act.

\footnotetext{
${ }^{2}$ https://www.forbesindia.com/blog/uncategorized/women-at-work-its-time-we-combat-the-culture-of objectification/\#: :text=In\%20India\%2C\%20objectification\%20is\%20ingrained,walk\%2C\%20talk\%2C\%20sing\%20etc.
} 


\subsection{Indecent representation of women's act amendment 2012}

Though the act of 1986 protects the women from being represented indecently, but this safeguard was restricted only to a limited extent. There were several paramount aspects to indecent representation which were deficient in this act. Thus, an amendment to this act was made in 2012 which widened the scope of this act by including several other varieties of communication, which are - 1) internet, 2) satellite and 3) television cable along with the augmentation of the term 'advertisements' to include what kind of advertisements have the scope under the act and 'distribution'. This amendment also makes the act inclusive of SMS, MMS which are new digital forms. One of the major changes also encompass the change in the definition of 'indecent representation', 'electronic media' and 'publish'. In addition to this there have also been amendments in penalties, which increased the term of imprisonment on the first convict from two years to three years and fine increased to between 50,000 and $1,00,000$ from 2,000 .

Besides these amendments, media is not depicting women as per the norms of IRWA, 1986. One of the major reasons behind this can be unawareness among the people of society about IRWA and its claiming procedure. In addition to this 'intention' is something which highly matters. In other words, this can mean that though today we are flooded with images, advertisements, video and other forms of media representing women indecently, but sometimes the reason behind the publishing of such media also is required to be bought into consideration. For instance - A porn is produced with the simple intention of fulfilling the sexual desires of a person, whereas in a movie which has a seen of intercourse between two people is a part of the entire movie and hence might be what the movie demands. Furthermore, we can also take the example of a movie director who wants to add a scene of intercourse between two people just to attract audience's attention and to zest up the movie. Similarly, the intention behind indecent representation needs to be taken into account and should punished accordingly.

\subsection{Legal guarantees provided under the constitution of India}

1) ${ }^{3}$ Article 14 - Equality before law cannot be denied to any person and also prohibits discrimination on the bases of religion, sex, race, caste or place of birth.

2) ${ }^{4}$ Article 15(3) - the state has to make special provisions for women and children for their melioration.

3) ${ }^{5}$ Article 16 - ensures equality of opportunity for all citizens in matters relating to public employment.

4) ${ }^{6}$ Article 39(a) - suggest that men and women have equally the right to an adequate means of livelihood and

5) ${ }^{7}$ Article 42 - ensures that the state makes enough provisions to secure just and humane conditions for women and for the maternity relief for women.

(6) Article 51(A) (e) - To promote harmony and the spirit of common brotherhood amongst all the people of India and to renounce practices derogatory to the dignity of women (Article 51(A) (e))

Under this act, it has been said that if a film receives the certificate based on its content then it shall not be liable to punishment in case of obscenity.

\subsection{Cinematograph Act, 1952}

According to this act anyone who has been granted the rights for a particular film cannot be acquitted under this act in respect to obscenity in matters subdued in the film because of the certificates that have been granted to them under clause (a) or clause (b)

However, there is no mention of indecent representation of women in this act as well as against the display of sexual violence against women. So, should we assume that the granting of a certificate is sufficient and gives the right to film directors to exploit women in whatever way they want? Hence, there should be more stringent laws against objectification and, rather than just providing with a 'UA' or 'A' certificate.

\footnotetext{
${ }^{3}$ The Constitution of India, 1950, Art. 14

${ }^{4}$ Ibid. Art. 15(3)

${ }^{5} / b i d$. Art. 16

${ }^{6}$ Ibid Art. 39(a)

${ }^{7}$ lbid. Art. 42
} 
3.5 Rule 6 of the Cable Television Network Rules, 1994

Programme code, (rule 6) of the act explicitly states that any event in the cable must not subdue any kind of insinuations or depictions which deliberately are obscene, defamatory, false or half-truths. Any programme which tries to disparage women through the exhibition of her body, her form or her body parts in a manner which seems to be improper and hence can deprave, corrupt or injure the public morality and should endeavour to lay out programmes which display woman to be empowered

3.6 Guidelines of the Central Board for Film Certification

The CBFC ensures that any scene which displays the retrogression of women in any way, or any scene which exhibits sexual violence against women like trying to molest a woman or rape her or involves sexual perversions. In fact, similar scenes must be circumvented and must not be shown intricately by minimising the details.

The guidelines of CBFC do not talk about the indecent representation of women. For instance - if a woman is sexualised in any way with a wrong intention (example- to grab attention of audience). Therefore, there needs to be a guideline regarding this issue as well

3.7 Section 13 and 14 of the Press Council Act, 1978

Section 13 of the ${ }^{8}$ Press Council Act, 1978 defines the objects and functions of the council and section 14 talks about the power to censor. The Press Council act, 1978 being one of the most predominant forms of communication does not talk about the correct representation of women.

3.8 Information technology act, 2000 (section 66, 67 and 67a)

Section 67 of the ${ }^{9} \mathrm{TT}$ Act, 2000 covers similar offences as has been covered under section 292 of Indian Penal, however the punishment for the offence varies. On the first conviction the term of imprisonment extends to five years and a fine of rupees five lakh. On the subsequent conviction the term of imprisonment extends to five years along with a fine of rupees 10 lakh.

Section 67A states the punishment for publishing or transmitting of material containing sexually explicit act, etc., in electronic form.

Both the sections, 67 and 67A of this act do not explicitly talk about women and hence can said as to be gender neutral. If one reads both these provisions precisely, then it is quite evident that these provisions bring forth the concern regarding creation, distribution and production of obscene and sexually explicit material. However, it has been witnessed that

The present usage of the existing laws under the IT Act, that would be shown through the case studies below, has almost laid a pathway to use the proposed amendments to fulfil only one part of the objective of the law, i.e., to prevent and punish the wrong doer for what these laws typically prescribe as 'illegal' under the Indian criminal justice system.

\subsection{Indian penal code}

Section 292

The sub-section one for the purpose of the section $292^{10}$ of the Indian Penal code states that any form of print, representation or object will be considered to be obscene if it is lewd or lecherous and intends to demean or corrupt a person who can hear, see or listen to the information embodied in it. The second sub-section of this act states that any person who is in possession of, tries to sell, buy, hire, circulate, import, export, advertise, tries to take part in a business which is known to be producing, purchasing, selling, exporting, publicly exhibiting or in any manner trying to put into circulation any form of print material, representation or object which is considered to be obscene shall be an offence under this section. The punishment for such an offence on the first conviction can be extended unto two years and a fine unto two thousand rupees. On the second conviction the term of imprisonment extends to up-to five years and a fine up-to Rupees five thousand.

\section{Section 293}

Under section $293^{11}$ Any person who tries to sell, distributes, lets to hire, exhibits or circulates any obscene print material, representation or object (as is referred to in section 292) to any person under the age of twenty years shall be punished with imprisonment which may extend to three years, and with fine which may extend to two thousand rupees, and, in the event of a

\footnotetext{
${ }^{8}$ Press Council Act, 1978, ss. 13,14.

${ }^{9}$ The Information Technology Act, 2000 (Act 21 of 2000), ss. 66,67,67A.

${ }^{10}$ The Indian Penal Code, 1860 (Act 45 of 1860), s.292.

${ }^{11}$ lbid. s. 293
} 
second or subsequent conviction, with imprisonment which may extend to seven years, and also with fine which may extend to five thousand rupees.

- The fine to be taken on offence under section 292 and 293 of Indian Penal Code are inadequate. In section 292 and 293 the fine on first conviction should be at least up to 20,000 and on second conviction should be up to rupees 50,000.

Section 294

Under section 29412, Any person who performs any obscene act in the public or sings, recites any ballad or words which are considered to be salacious shall be punished with imprisonment of three months or with a fine or both.

\section{Section 509}

Under section $509^{13}$, it states that anyone who through any sound, words, gestures, by showing any object which intends to insult the modesty of woman or tries to intrude the privacy of the woman shall be punished with imprisonment for a term which may extend to three years, and also with fine.

\section{Ratifications of International treaties by India for protection of women}

International Covenant on Civil and Political Rights on April 10, 1979, however, not signed or ratified the optional protocols to the ICCPR (including the Second Optional Protocol, which abolishes death penalty) ${ }^{14}$.

\section{ICESCR}

The International Covenant on Economic, Social and Cultural Rights on April 10, 1979, however, did not sign or ratified the optional protocol to the ICESCR ${ }^{15}$.

\section{Convention on the Political Rights of Women}

The Convention on the Political Rights of Women was approved by the United Nations General Assembly during the 409th plenary meeting, on 20 December 1952, and adopted on 31 March 1953. The Convention's purpose is to codify a basic international standard for women's political rights. Signed on April 29, 1953 and ratified it on November 1, 1961'16.

\section{Convention on Elimination on all forms of Discrimination against Women}

On 18 December 1979, the Convention on the Elimination of All Forms of Discrimination against Women was adopted by the United Nations General Assembly. It entered into force as an international treaty on 3 September 1981 after the twentieth country had ratified it. By the tenth anniversary of the Convention in 1989, almost one hundred nations have agreed to be bound by its provisions. The Convention was the culmination of more than thirty years of work by the United Nations Commission on the Status of Women, a body established in 1946 to monitor the situation of women and to promote women's rights. The Commission's work has been instrumental in bringing to light all the areas in which women are denied equality with men. These efforts for the advancement of women have resulted in several declarations and conventions, of which the Convention on the Elimination of All Forms of Discrimination against Women is the central and most comprehensive document. Signed on 25th June $1993^{17}$.

\section{Beijing Principles of the Independence of Judiciary}

It was drawn up and agreed to in 1995 by the Chief Justices of countries in the Asia-Pacific region. ${ }^{18}$

\section{UN Women}

It's Office based in New Delhi covers four countries: India, Bhutan, Maldives and Sri Lanka. In these countries, women's rights are strengthened by working with women, men, feminists, women's networks, governments, local authorities and civil society. Ending violence against women, Promoting Leadership and Participation, National planning and budgeting, Economic Empowerment, Peace and Security and Migration are the six main priority areas that UN women stand for. ${ }^{19}$

\footnotetext{
12 Ibid. s. 294

${ }^{13}$ Ibid. s. 509

${ }^{14}$ https://www.ohchr.org/en/professionalinterest/pages/ccpr.aspx

${ }^{15} \mathrm{https}$ ://www.ohchr.org/en/professionalinterest/pages/cescr.aspx

${ }^{16} \mathrm{https} / / /$ en.wikipedia.org/wiki/Convention_on_the_Political_Rights_of_Women

${ }^{17}$ https://www.ohchr.org/en/professionalinterest/pages/cedaw.aspx

${ }^{18}$ https://www.ru.nl/publish/pages/688605/beijing-eng.pdf

19 https://www.unwomen.org/en/about-us/about-un-women
} 


\section{Role of culture in objectification of women: a cross country analysis}

Fredrickson and Roberts (1997) in their objectification theory have explicitly described how a woman's body is built through various socio- cultural processes and discussions as a result of them living in innumerable cultures. "Bodies exist within social and cultural contexts, and hence are also constructed through sociocultural practices and discourses" (p. 174). One of the major concerns is to consider is the magnitude of culture affecting people's tendency to objectify themselves or others and along with this we must consider that the dehumanisation faced by sexually objectified victims is the same among all cultures. We can say that culture is primary to sexual objectification. Anglophone nations (e.g., Australia, the UK, the US) are the ones from where the maximum amount of objectification takes place according to evidences, along with Western European (e.g., Belgium, Italy).

Steve Loughnan (2015), in his paper has tested traditional (i.e., Australia, Italy, the UK, and the US) as well non-traditional (i.e., India, Japan, and Pakistan) nations of objectification. This study corroborates the notion that culture really matters in studying sexual objectification. Furthermore, it has been displayed that the non-traditional nations show low levels of trait and other types of objectification. The fact that people in Indian, Pakistani, and Japanese express sexual objectification to a lesser extent than Westerners, cannot make us conclude that the people in these non-traditional countries face any less objectification. It was also witnessed that across different cultures the sexualized victims were considered of deserving less moral respect than normal people. Similarly, Wollast (2018) in his paper found that sexual objectification leading to dehumanization exists in both, Eastern and Western culture. However, in his paper it has been said that "the effect of target sexualisation on dehumanisation is a more general, rather than culture-specific, phenomenon." In conclusion this paper says that objectification is not exclusively present in the Western culture but exists to great extent in Eastern culture as well. Two major factors focussed on by this study were 1) clothes (dresses vs. non-dressed) and 2) posture (suggestive vs. neutral).

- Belgium, France, Finland, Greece, Norway, South Africa and India, which have laws or codes of varying degrees and age that prevent gender discrimination in ads.

- Norway - law prohibiting sexism in ads since 1978

- Spain - law against gender violence prohibits ads from showing degrading images of a woman's body, 2004

- Australia - Austrian codes consider depictions that reduce a person to their sexuality discriminatory.

- United States of America - According to a report by the American Psychological Association ${ }^{20}$ (APA) the women and girls are objectified more often in various ways, such as displaying them with a bodily heavy postures and facial expressions that seem to show sexual readiness. It was found out by Wesley university that women were featured as sex objects in $51.8 \%$ of the magazines, however this objectification increased to $76 \%$ when women were showed with men (out of 58 magazines). In the U.S., guidelines on stereotypes in advertising are only offered by the group that oversees ads that target children.

- Despite this, I was not able to find any particular law that exists in USA to prevent indecent representation of women and girls. CEDAW has repeatedly called upon states, including the UK, to tackle the objectification of women in the media because of the attitudes and behaviors that 'sex object culture' promotes.

- United Kingdom - UK in contrast to USA still has some laws regarding indecent representation of women.

- 4.9 (CAP Code) and 4.14 (BCAP Code) - introduced by CAP for preventing gender stereotyping in ads. These were introduced on 14 December 2018 and 14 June 2019. This rule states that ads 'must not include gender stereotypes that are likely to cause harm, or serious or widespread offence'.

- Thus, UK's Advertising Standards Authority has banned ads which have a connotation with gender stereotypes, which encompass even broadcast media, as well as to online and social media. For instance- men unable to change diapers, women doing house chores when men simply lying on the couch etc. Furthermore, steps for banning advertisements which associate outer appearance with doing well in other spheres of life.

- Nicaragua - In Nicaragua, there is a culture called 'machismo' according to which, 'machistas' are men who objectify women.

- In order to eradicate this culture and overcome the pre-established gender roles by macho society the Masculinity Network for Gender Equality organization have taken several measures which have in turn transformed men's "machista" behaviors.

- South Africa- The ASA (advertising Standard Authority) in South Africa has taken several measures on the state of the advertising and marketing industry in South Africa in regard to racism. However, there are no significant laws in south Africa against objectification of women. By the comparative analysis of these 5 countries (USA, UK, Nicaragua, South Africa, India), it has been witnessed that objectification of women exists in each one of these, though the degree of objectification may differ. What I can conclude by this comparative analysis is that there exists no particular law or act in any of these countries (except India). However, there is some awareness in these countries regarding objectification because of indecent representation of women which is limited to advertiseme

20 https://www.apa.org/pi/women/programs/girls/report-full.pdf 


\section{Gap Analysis}

A survey of the sociological as well as the legal literature as well as an analysis of the existing legal frameworks underpinning the protection of women against objectification has laid bare some gaps that need to be addressed in order to comprehensively deal with the menace of objectification of women in India.

The gaps have been listed below:

1. The basic definition of "Indecent representation" remains vague and open to interpretation even in the IRWA amendment 2012.

2. What exactly accounts to be objectification? Is it showing too much of skin or being nude. Both of them will not account to objectification until a female or a male is doing it to fulfil someone else's sexual desires or is being used as a commodity. Not a clear understanding on this subject is one of the main reasons why women victims are blamed by the orthodox society or even the officials as having shown too much skin which would have prompted the society to commit the crime.

3. The expression of sexuality is equated with obscenity.

4. The concept of indecent representation of women must be freed from patriarchal meanings of social value and morality.

5. The Indian legal understanding of the concept of obscenity and pornography have almost always overlapped with each other due to colonial regulations, especially Section 292 of the Indian Penal Code. The term 'indecency' is relatively new to cap the concept of portrayal of materials which does not actually fall in the typical meaning of obscenity, but falls in the spectrum of other sexual materials which may be immoral. However, the definition is still too vague, leaving the ground open for misuse.

6. The Cinematograph Act 1952 does not take into account the tenets of IRWA 1986

7. The guidelines for certification under CBFC are not sensitive to the concerns of IRWA

8. The punitive actions under the current legal framework for production and distribution under sections 292 and 293 of the IPC are inadequate

9. Section 509 of the IPC needs to be strengthened in terms of victimization of women through fake avatars. In cases of victimization of women through fake avatars (including avatars made with visual images or through verbal descriptions as happens in bullying and trolling) the criminal justice administration including the police and the judiciary most often leave the offender on bail after charging a fine or confiscating the hardware devices. This provides a huge chance for the offender to come back with a new identity and new devices to take revenge on the victim.

10. The intention to cause damage should be incorporated into the provisions of the act. Social media and adult sites are being misused for degrading portrayals of women not only by men but also by women. Unless the intention to cause damage is incorporated in the provisions meant for definition of the concept of Indecent Representation of Women (Prohibition) Act and also in the related provisions in Information Technology Act and the Indian Penal Code, which are often roped into to support the provisions in the Indecent Representation of Women (Prohibition) Act; and the suggestions that this paper provides towards preventing the victimization are considered for the future amendments for laws meant to prevent cyber victimization of women through indecent, false derogatory fake avatars, the victimization of women in the cyber space may become an unending example of the result of faulty laws.

11. Section 294 dealing with obscene actions in public is also weak from a punitive standpoint

12. The Press Council act, 1978 related to one of the most predominant forms of communication does not talk about the correct representation of women.

13. Sections 66,67 and 67 A of the IT Act, 2000 are gender neutral currently and need to be amended to safeguard against objectification of women. What is needed is a gender-specific Statute which acts as an enabling provision for countering the presence of such non-consensual material over the web like "revenge porn"

14. None of the acts protect the women who themselves contribute images which can be showing too much of skin or can be semi-nude from various crimes and the objectification they might go through.

15. No succor is provided to the victim in the form of compensations or counselling etc. Not only does the derogatory, false and indecent avatar remain 'alive' for a long time to create huge embarrassment for the victim, it may also deter her professional as well as personal reputation as a person with clean moral values. In reality, this makes the victim extremely traumatized and may actually hamper her professional and personal life. The effect of the alive and floating fake avatar or the news report publishing the victimization may be further traumatizing for the victim. The victim may lose her job, her family members may be ridiculed and her children may be targeted in school. Added with mental trauma, financial losses may affect the victim as well as her family.

16. The "Right to be forgotten" must be incorporated as objectionable content should be deleted in its entirety in all its forms, digitally and physically. 
17. Section 509 of the Indian Penal Code, does not specifically mention about the medium of the harassment. Also, it does not specifically touch the offensive sexual innuendo factor. The provision fails here when the fake avatars are essentially created to portray the woman in an indecent fashion and as a sexual object which carries a worse connotation than simple "insult to the modesty". Nonetheless, in Indian socio-legal understanding, modesty of women has almost always been understood in the light of feminine decency and sexual reputation. But the concept of offensive sexual innuendo through victimisation through fake avatars in cyber space may have a far deeper impact than the concept of modesty as understood in Section 509 of the Indian Penal Code. This is because it may indicate offensive physical exhibition of the victim through cyber space and may actually hamper the victim woman's right to equality and the right to live with dignity.

18. The drawback from which all these provisions suffer lies in the language which indicates "no person shall publish" (Section 3 of the Indecent Representation Of Women (Prohibition) Act), 'no person shall produce or cause to be produced..." (Section 4 of the Indecent Representation Of Women (Prohibition) Act), "whoever publishes or transmits..." (the starting words for both Sections 67 and 67A of the I.T.Act). In this age of "Third Wave Feminism", this has definitely a chilling effect to the right to freedom of speech and expression as has been guaranteed under Article 19(1) (a) of the Constitution of India, which guarantees all citizens the right to freedom of speech and expression. At the same time, the target-section of all these provisions, i.e. 'whoever' also brings back these provisions within the purview of the 'reasonable restrictions' on the ground of 'decency' or 'morality', as has been stated in Article 19(2) of the Constitution. The language of the law must be amended to properly indicate the actual offender's responsibility rather than using the term "whoever" holistically. This would make the law more victim-friendly.

19. Further, it needs to be remembered that merely by prescribing jail terms or fine as punishment, cyber victimization cannot be prevented. The responsibility of the online service providers like Google, Facebook or Twitter which are actually hosted in the US, are almost blind when it comes to question of monitoring the usage of subscribers through creating new identities and using the social media or web platforms for further harassment of the victims.

20. In India presently there exists no stringent system of usage of uniform identification number for creating an email account or getting a mobile SIM card. This encourages the perpetrator to come back with new identities availing new/old service providers to re-victimize the victims. In such cases, deterrent steps like banning the offender from contacting the victim through digital communication media or making the social media aware by serving a preventive and monitoring notice against the perpetrator user can prove fruitful. The Indecent Representation of Women (Prohibition) Act as well as the Information Technology Act must consider such preventive actions to prevent cases of cyber victimization, especially victimization of women.

21. The penalties under IRWA 1986 and IRWA (amended) 2012, need to be made in line with the Information Technology Act, 2000

22. As proposed in the amended IRWA act of 2012, a centralised authority under the aegis of the NCW needs to be created with authority to receive complaints or grievances regarding any programme or advertisement broadcast or publication and investigate/ examine all matters relating to the indecent representation of women. This authority may be headed by Member Secretary, NCW, having representatives from Advertising Standards Council of India, Press Council of India, ministry of information and broadcasting and one member having experience of working on women issues.

\section{Research Methodology}

Based on the secondary research as outlined in the literature cited above, gaps were identified in the Indian legal frameworks dealing with objectification of women. The same have been outlined in the "Gap Analysis" section above. In order to frame recommendations to ally these gaps, two approaches were taken:

- Primary Research

- Secondary Research

\subsection{Primary Research}

Under primary research the gaps identified were formulated in the form of a questionnaire. A panel of socio-legal experts with knowledge and experience of working in the field of female rights. The questionnaire was then circulated to this cross section of socio-legal experts to solicit their opinion regarding the gaps and ways to plus those gaps by amendments across various laws, including laws specifically for objectification of women like IRWA but also ancillary laws like the IT act as well as the IPC.

Once the questionnaire (Appendix A) was shared, it was followed by a telephone interview with the lawyers and judges (Mentioned in Appendix B), who were first explained the whole research paper in detail then were given a week to study the topic thoroughly. A week later, they were given the questionnaire to be filled via mail. The questionnaire was filled up and was given back to me within 2 weeks. 
On the basis of the responses received the recommendations were formulated.

\subsection{Secondary Research}

The initial recommendations were further supplemented by the secondary research undertaken by studying articles ${ }^{21}$ and papers (Choudhury, 2014; Bhandari, 2018; Bhattacharjee, 2019 etc.) highlighting the changes required in Indecent Representation of Women Act 1986. These changes were further added to the recommendations by socio-legal experts.

As the third step, inputs from the cross country analysis that was undertaken was also added to the recommendations so as to arrive at a consolidated list of recommendations.

The process that we followed is given in the figure below:

Figure 1: Qualitative Research Process

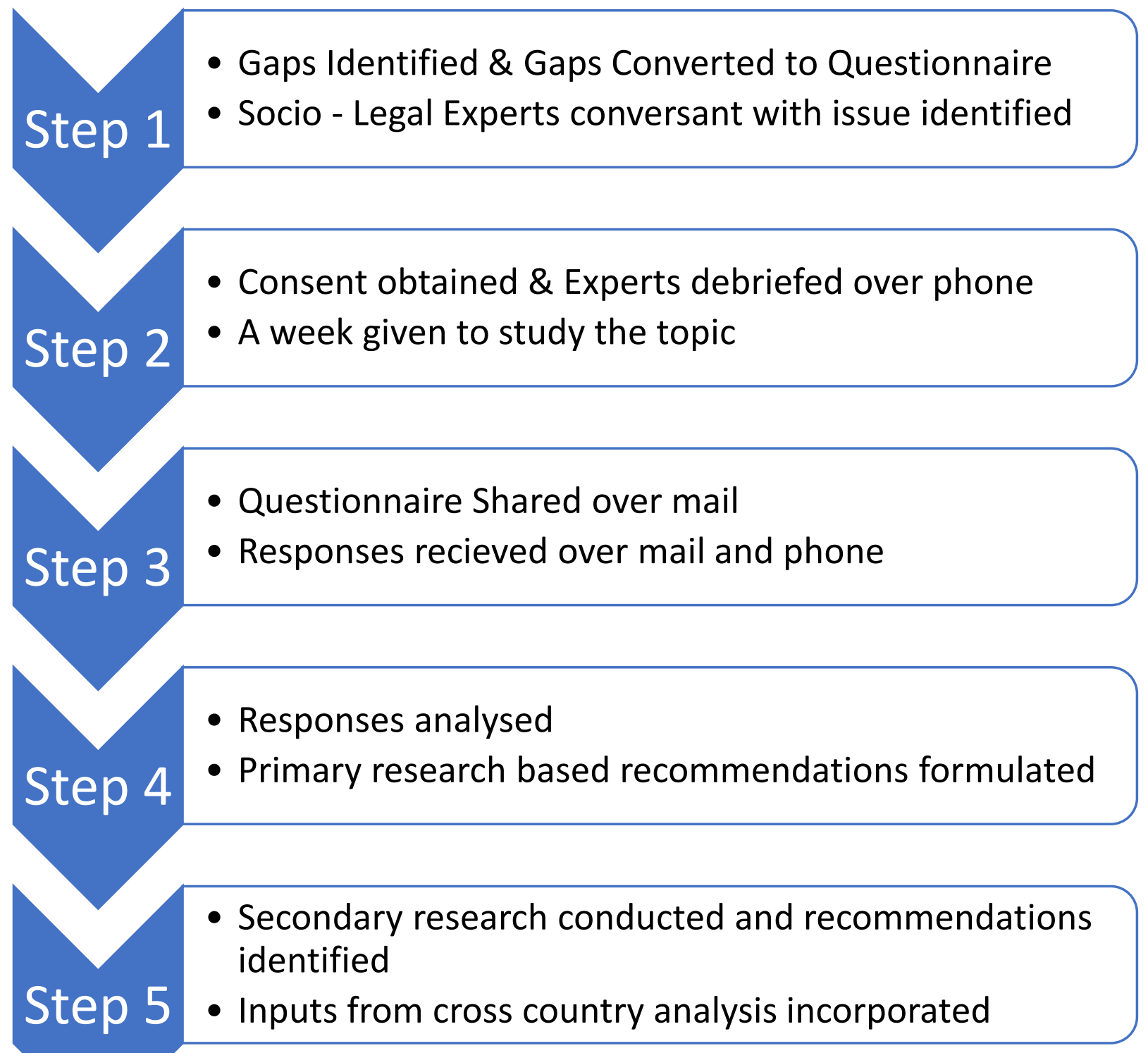

\footnotetext{
${ }^{21}$ https://feminisminindia.com/2017/02/09/indecent-representation-women/
} 
The questionnaire is shared in the form of Appendix $A$ and the list of respondents in Appendix $B$.

\section{Recommendations}

\subsection{Education System}

a) Gender neutral education - Several preschools in Sweden have adopted an approach which aims at instilling gender neutral education. I robustly believe schools in India and other countries can adapt this approach. This is because preschool is the stage from where a child begins to be aware of his/her surroundings and develop a sense of what should they be wearing, with which toys should they be playing with and so on. This is the grassroot level from which gender stereotypes start developing among children, who profoundly grasp what they learn from their surroundings.

b) Awareness Programmes - Awareness is the key through which we can not only make students aware about what is objectification and they regularly face objectification in their daily life, but are not able to do anything, just because they do not know about. For instance- though women are still facing discrimination and have to go through a lot, but the rising awareness among people about the fact that women need to respected, treated equally makes it easier to raise voice against those who do not think along the same lines.

\subsection{Changes in laws}

a) Anti-objectification law- An anti- objectification law must exist in all countries which must prevent gender stereotypes along with putting restrictions on using women as an object or a commodity to fulfil someone else's desire (sexual). In several countries as shown in the cross country analysis there exists no specific law pertaining to objectification of women on various platforms (print, digital, electronic media, social media platforms, paintings, sculptures) or even in daily life, for that matter. Since there is a very thin line of differentiation between indecent representation and patriarchy and male chauvinism (wherein women are judged on the basis of what they wear or do) 'intention' is something which highly matters. In other words, this can mean that though today we are flooded with images, advertisements, video and other forms of media representing women indecently, but sometimes the reason behind the publishing of such media also needs to be taken into account. For instance - A porn is produced with the simple intention of fulfilling the sexual desires of a person, whereas in a movie which has a seen of intercourse between two people is a part of the entire movie and hence might be what the movie demands. Furthermore, we can also take the example of a movie director who wants to add a scene of intercourse between two people just to attract audience's attention and to zest up the movie. Similarly, the intention behind indecent representation needs to be taken into account and should punished accordingly. Hence, in my opinion there must be a provision wherein the intention of the person producing material needs to be there.

b) Compensation - Since the impact of such objectification can adversely affect the person. It can have an impact on the person's social and work life and the person can even go through depression or other psychological impacts, therefore there ought to be a provision of compensation for the victims. The compensation can vary with the varying degree of the crime committed. The compensation can even be in the form of counselling for minor crimes. However, there needs to be a proper distinction and layout of what is a minor and what is a major crime.

c) Victim safety - another provision of the act must encompass the victim safety, which means that several women do not complain against the objectification that they face (in various ways) as they fear that their reputation in the society would be at stake if they cavil against the objectifier.

d) The law must cover obscene actions in public

e) There ought to be a provision wherein women who themselves contribute images that can be showing too much skin or can be semi-nude from various crimes and the objectification they might go through.

f) Right to be forgotten - that citizens no longer need to file a case in order to request for information from search engines to be removed. This case could have significant impacts on the right to be forgotten and search engines. An individual can make a request to a data controller that all of their personal data be erased without "undue delay" and with no cost to the person making the request. This includes files, records in a database, replicated copies, backup copies and any copies that may have been moved into an archive. Thus, every country should have the 'right to be forgotten'.

\subsection{Raising Public Awareness and Consciousness}

There must be a focus on uncoupling perfect body type (physical attractiveness) away from consumer products. Furthermore, a reappraisal of the existing 'accepted' digital techniques would be logical, as they include cropping and digital manipulation. (Borgenson \& Schroeder (2004, p. 14) regarding the relationship between cropping techniques and objectification). Berman (2009, p.1) states: 
"Designers have an essential social responsibility because design is at the core of the world's largest challenges... and solutions. Designers create so much of the world we live in, the things we consume, and the expectations we seek to fulfil. They shape what we see, what we use, and what we waste. Designers have enormous power to influence how we engage our world, and how we envision our future."

This means that the undertaking of spreading deep personal awareness and sensitising should be prioritized. This self-regulatory ethical design process, based on the ideas by Berman (2009), the work of Nussbaum (1995) and Langton (2009) is as follows:

A question that one needs to ask themselves is if they would grant the license to someone else and permit them to portray you as one of the following -

a) Someone lacking self-determination, ascertainment and wisdom?

b) Someone whose credentials are lower as compared to a consumer product.

c) Someone who does not have basic etiquettes and ethics?

d) Someone who is willing to be with those who provides them with the highest amount of pay.

e) Someone who is willing to be used as an instrument for other people's Sexual gratification.

f) Someone who is just being utilized because of their outer appearance, while completely ignoring your internal virtues.

\section{References}

[1] Archer, D., Iritani, B., Kimes, D. D., \& Barrios, M. (1983). Face-ism: Five studies of sex differences in facial prominence. Journal of Personality and Social Psychology, 45(4), 725-735. doi: https://doi.org/10.1037/0022-3514.45.4.725

[2] Arluke, A.B. (1988). Sacrificial Symbolism in Animal Experimentation: Object or Pet?. Anthrozoös, 2(2), 98-117. doi: $10.2752 / 089279389787058091$

[3] Aubrey, J.S., \& Cynthia M.F. (2011). Sexual Objectification in Music Videos: A Content Analysis Comparing Gender and Genre. Mass Communication and Society, 14(4), 475-501, doi: 10.1080/15205436.2010.513468.

[4] Aubrey, J. S., Henson, J., Hopper, K. M., \& Smith, S. (2009). A picture is worth twenty words (about the self): Testing the priming influence of visual sexual objectification on women

[5] Aubrey, J. S. (2007). The impact of sexually objectifying media on negative body emotions and sexual self-perceptions: Investigating the mediating role of body self-consciousness. Mass Communication \& Society, 10,1-23.

[6] Aubrey, J. S. (2006). Effects of sexually objectifying media on self-objectification and body surveillance in undergraduates: Results of a twoyear panel study. Journal of Communication, 56, 366- 386.

[7] Austrian Advertising Council valid from the 1st June 2012 The self-regulating body of the Austrian advertising industry.

[8] Balraj, B. (2015). Understanding objectification theory. International Journal on Studies in English Language and Literature, 3, 70-74. Braun, V. and Clarke, V. (2006). Using thematic analysis in psychology. Research in Psychology, 3(2), 77-101.

[9] Bhandari, I.K. (2018). Commodification of Women body in Indian media. International Journal of Research and Analytical Reviews, 5 (3), 979-981

[10] Bauer, N. (2011). Beauvoir on the Allure of Self-Objectification. In S.D, Beauvoir (Ed.). Feminist Metaphysics, Feminist Philosophy Collection ( $5^{\text {th }}$ ed., pp. 117-129). Berlin, Germany: Springer

[11] Cheek, N.N. (2016). Face-ism and Objectification in Mainstream and LGBT Magazines. Plos one, 11(4): e0153592. doi:10.1371/journal.pone.0153592

[12] Choudhury, P. (2014). Role of Media and Indecent Representation of Women. IOSR Journal Of Humanities And Social Science, 19(11), 33-36. http://www.iosrjournals.org/iosr-jhss/papers/Vol19-issue11/Version-8/H0191183336.pdf

[13] Committee of Advertising Practice Ltd. (CAP). (2019, June 14). Offence: Use of stereotypes. asa.org.uk. Retrieved from https://www.asa.org.uk/advice-online/offence-use-of-stereotypes.html

[14] Constitution of India , Art.226, Art.21- Penal Code (45 of 1860) , S.292 (Para 20 23), 1996 Cri LJ 2725 (Del)

[15] Davis, S.E. (2018). Objectification, Sexualization, and Misrepresentation: Social Media and the College Experience. Social media+Society, 4(3), 1-9. doi:10.1177/2056305118786727

[16] Desai, R. (2019). U.K. Bans Advertisers From Using Gender Stereotypes to Market Products. The Swaddle. https://theswaddle.com/u-kbans-advertisers-from-using-gender-stereotypes-to-market-products/.

[17] Dowarah, T. (2010). Legal Protection of Women under the constitution of India (Unpublished Bachelor's dissertation). Dibrugarh University, Dibrugarh. https://www.scribd.com/doc/51644251/LEGAL-PROTECTIONS-OF-WOMEN-UNDER-THE-CONSTITUTION-OF-INDIA-BYTEZOSWIE-DOWARAH

[18] Drury, K.M. (2015). Through a different lens: Adolescent sexual health in the context of gender, the body, close relationships and well-being. (Unpublished master's thesis). Department of Psychology, Concordia University, Montreal, Québec, Canada. https://spectrum.library.concordia.ca/980545/1/Drury PhD F2015.pdf

[19] Face-ism. (2020, December 24). In Wikepedia. http://en.wikipedia.org/wiki/Face-ism

[20] Fredrickson, B.L., \& Roberts, T.A. (1997). Objectification Theory: Towards Understanding Women Lived Experiences and Mental Health risks. Psychology of women Quarterly, 21(2), 173- 206. doi:10.1111/j.1471-6402.1997.tb00108.x.

[21] Giri, B. Legal Protection Of Women: An analytical study with special reference to Dowry deaths in the state of Jharkhand (Unpublished Thesis). University of Burdwan, Burdwan. http://shodhganga.inflibnet.ac.in/bitstream/10603/68537/1/bhanu\%20giri,\%20thesis.pdf

[22] Good Reads. (2020, November 26). Objectification. Retrieved from https://www.goodtherapy.org/blog/psychpedia/definition-ofobjectification. 
[23] Gor, R.A. (2018). Objectification of Woman in Media. International Journal of Research in all Subjects in Multi Languages, 6 (3), $84-87$.

[24] Gresh, E. (2017). Machismo Culture and Women's Empowerment in Nicaragua. The Borgen Project, https://borgenproject.org/womensempowerment-in-nicaragua.

[25] Gupta, M.D. (2018). Law against indecent depiction of women on anvil; will cover WhatsApp, Snapchat, Instagram. Hindustan Times. https://www.hindustantimes.com/india-news/soon-a-law-against-women-s-indecent-depiction-to-cover-whatsapp-snapchat-instagramgovernment/story-

[26] Holland, E., Koval, P., Stratemeyer, M., Thomson, F., and Haslam, K. (2016). Sexual objectification in women's daily lives: A smartphone ecological momentary assessment study. The British Psychological Society, 56(2), 1-20. doi: 10.1111/bjso.12152

[27] Honap, R. (2016), The Criminal Law Amendment 2013 and Gender Equality, Dnyanamay, 1(4), 17-21. https://www.lawctopus.com/academike/criminal-law-amendment

[28] Inge, E., \& Rudi, L. (2015). Addressing objectifying media portrayals of women in South Africa [Conference Presentation]. Design Education Forum of Southern Africa, Pretoria, South Africa. https://www.defsa.org.za/papers/re-representation-addressing.

[29] Kakodar v. The State Of Maharashtra AIR 1390 SCR (2) 80

[30] Kellie, D.J., Blake K.R., Brooks, R.C. (2019). What drives female objectification? An investigation of appearance-based interpersonal perceptions and the objectification of women. Plos one, 14(8): e0221388. https://doi.org/10.1371/journal.pone.0221388

[31] Langton, R. (2009). Sexual Solipsism: Philosophical Essays on Pornography and Objectification. Oxford: Oxford University Press.

[32] Langton, R. (1995). Sexual Solipsism. Philosophical Topics, 23(2), 181-219.

[33] Loughnan, S., Fernandez-Campos, S., Vaes, J., Anjum, G., Aziz, M., Harada, C., Holland, E., Singh, I., \& Puvia, E., \& Tsuchiya, K. (2015). Exploring the role of culture in sexual objectification: A seven nations study. Revue internationale de psychologie sociale, 28(1), 125152. doi: https://doi.org/.

[34] MacKinnon, C.A. (1993). Racial and Sexual Harassment. In MacKinnon, C.A. (Ed.).Only Words (15t ed. pp. 86-123). Cambridge Massachusetts: Harvard University Press

[35] MacKinnon, C.A. (1987). Pornography. In MacKinnon, C.A. (Ed.). Feminism Unmodified: Discourses on Law and Life(15t ed., pp. 127-146). Cambridge, Massachusetts: Harvard University Press

[36] Nussbaum, M. (1995). Objectification. Philosophy \& Public Affairs. 24(4), 249-291. doi: https://doi.org/10.1111/j.1088-4963.1995.tb00032.x.

[37] Papadaki, E. (2020). Feminist Perspectives on Objectification. Stanford Encyclopedia of Philosophy Archive. https://stanford.library.sydney.edu.au/archives/sum2020/entries/feminism-objectification/

[38] Papadaki, E. (2007). Sexual objectification: From Kant to contemporary feminism. Contemporary Political Theory, 6, $330-348$.

[39] Putri, L.A. (2020). Objectification Suffered by Black women in Suzan Lori Parks'Venus. Universitas Islam Nigeria. http://etheses.uinmalang.ac.id/18692/1/16320058.pdf.

[40] Quinn, D. M., Chaudoir, S. R., \& Kallen, R. W. (2011). Performance and flow: A review and integration of self-objectification research. In R. Calogero, S. Tantleff-Dunn, \& K. Thompson (Eds.), Self-objectification in women: Causes, consequences, and counteractions (pp. 23-49). Washington, DC: American Psychological Association.

[41] Ramo, S. (2012). Greater action must be taken in combating the sexual objectification of women in the print media. LSE blogs. https://blogs.Ise.ac.uk/politicsandpolicy/sexual-objectification-page-3/

[42] Rouse, M. (2019, February). Right to be Forgotten. Search Content management. https://searchcontentmanagement.techtarget.com/definition/The-right-to-be-forgotten

[43] Sarah, J., Gervais, S.J., Saez G., Riemer, A.R. \& Klein, O. (2020). The Social Interaction Model of Objectification: A process model of goalbased objectifying exchanges between men and women. British Journal of Social Psychology, 59(1), 248-283. doi: https://doi.org/10.1111/bjso.12339.

[44] Seidman, S. A. (1992). An investigation of sex-role stereotyping in music videos. Journal of Broadcasting \& Electronic Media, 36, $209-216$.

[45] Shah v. Ramaswami, Grover AIR 1396 SCR (2) 80

[46] Slatewala, Z.Z. (2019). Objectification of Women in Bollywood Item Numbers. Graduate Theses and Dissertations, https://scholarcommons.usf.edu/etd/7948.

[47] Special Feature Annual Report (2012). JTRI Journal, Issue 33. Retrieved from https://es.scribd.com/document/180415644/JTRI-Journal-2012pd

[48] Stephanie V. Ng. (2016). Social Media and the Sexualization of Adolescent Girls. American Journal of Psychiatry Residents' Journal, 11(12), 560 - 577. doi: https://doi.org/10.1176/appi.ajp-rj.2016.111206.

[49] Sudkämper, A., Ryan, M.K., Kirby, TA. \& Morgenroth, T. A. (2019). Comprehensive measure of attitudes and behaviour: Development of the Support for Gender Equality among Men Scale. Eur J Soc Psychol, 50(2), 256- 277. https://doi.org/10.1002/ejsp.2629

[50] Swift, J., \& Gould, H. (2020). Not An Object: On Sexualization and Exploitation of Women and Girls. UNICEF. https://www.unicefusa.org/stories/not-object-sexualization-and-exploitation-women-and-girls/30366.

[51] Szymansk, D.M., Moffitt, L.B., \& Carr E.R. (2011). Sexual Objectification of Women: Advances to Theory and Research. The Counseling Psychologist, 39(1), 6-38, doi: 10.1177/0011000010378402

[52] The indecent representation of women (prohibition) act 1986 act no. 60 of 1986. National Commission for Women in India. [23rd December, 1986.] http://ncw.nic.in/acts/ThelndecentRepresentationofWomenProhibitionAct1986.pdf

[53] Udeshi v. State Of Maharashtra AIR 881 SCR (1) 65

[54] Valeriya Safronova. (2019).Gender Stereotypes Banned in British Advertising. The New York Times. https://www.nytimes.com/2019/06/14/style/uk-gender-stereotype-ads-ban.html

[55] Whisnant, R. (2017). Feminist Perspectives on Rape. Stanford Encyclopedia of Philosophy. http://documents.mx/documents/feministperspectives-on-objectification.html. 
[56] Wollast, R., Puvia, E., Bernard, P., Tevichapong, P., \& Klein, O. (2018). How Sexual Objectification Generates Dehumanization in Western and Eastern Cultures - a Comparison Between Belgium and Thailand. Swiss Journal of Psychology, 77(2), 69-82. doi: 10.1024/1421$\underline{0185 / a 000209 .}$

[57] Zaidi, N. (2015). Human Rights of weaker Sections in Islam with special reference to Women and Children. http://ir.amu.ac.in/9858/1/T9664.pdf

Appendix 1

1) How can the basic definition of "Indecent representation under IRWA amendment 2012 be further expanded to remove ambiguity if any?

2) How do ensure that expression of sexuality is not equated with obscenity under various laws?

3) How do ensure that the concept of indecent representation of women is freed from patriarchal meanings of social value and morality.

4) How do we differentiate between the Pornography, Obscenity and Indecency?

5) Does the Cinematograph Act 1952 need to take into account the tenets of IRWA and if so how?

6) The guidelines for certification under CBFC are not sensitive to the concerns of IRWA. Your comments and suggestions?

7) vbgbHow can the punitive actions under the current legal framework for production and distribution under sections 292 and 293 of the IPC be strengthened?

8) Section 509 of the IPC needs to be strengthened in terms of victimization of women through fake avatars. Suggestions?

9) How do we prevent the victimization of women through fake avatars (including avatars made with visual images or through verbal descriptions as happens in bullying and trolling)?

10) In cases of victimization of women through fake avatars the criminal justice administration including the police and the judiciary most often leaves the offender on bail after charging a fine or confiscating the hardware devices. This provides a huge chance for the offender to come back with a new identity and new devices to take revenge on the victim. How do we plug this loophole?

11) Should the intention to cause damage be incorporated into the provisions of the IRWA act, IT act and the Indian Penal Code?

12) How should Section 294 dealing with obscene actions in public be strengthened from a punitive standpoint

13) The Press Council act, 1978 related to one of the most predominant forms of communication does not talk about the correct representation of women. How do we amend the same?

14) Sections 66, 67, and 67A of the IT Act, 2000 are gender-neutral currently and need to be amended to safeguard against the objectification of women. What is needed is a gender-specific Statute which acts as an enabling provision for countering the presence of such non-consensual material over the web like "revenge porn". Do you agree or disagree and if so why?

15) Currently neither the IRWA nor any other legal provisions in the Indian legal system protect the women who themselves contribute images that can be showing too much skin or can be semi-nude from various crimes and the objectification they might go through. How can this be achieved?

16) Currently no succour is provided to the victim in the form of compensations or counselling etc. How can we create support mechanisms to help women deal with the after effects of the derogatory, false and indecent avatar remain 'alive' for a long time to create huge embarrassment for the victim, and may also deter her professional as well as personal reputation as a person with clean moral values?

17) What are your views on the "Right to be forgotten?" Should it made legally binding that all objectionable content be deleted in its entirety in all its forms, digitally and physically

18) How do we augment Section 509 of the Indian Penal Code which in its current form does not specifically mention the medium of the harassment? Also, it does not specifically touch the offensive sexual innuendo factor. The provision fails here when the fake avatars are essentially created to portray the woman in an indecent fashion and as a sexual object which carries a worse connotation than simple "insult to the modesty".

19) How do we strengthen the concept of modesty as understood in Section 509 of the Indian Penal Code such that it protects the victim woman's right to equality and the right to live with dignity?

20) How do we amend the language of the various law to properly indicate the actual offender's responsibility rather than using the term "whoever" holistically thus make the law more victim-friendly?

21) How do we hold online service providers like Google, Facebook or Twitter which are hosted in the US, accountable towards monitoring the usage of subscribers in order to prevent harassment of women?

22) How do we formulate a stringent system of usage of the uniform identification number for creating an email account or getting a mobile SIM card in order to prevent perpetrators from coming back with new identities availing new/old service providers to revictimize the victims?

23) What steps need to be taken to bring the penalties under IRWA 1986 and IRWA (amended) 2012, need to be made in line with the Information Technology Act, 2000

24) As proposed in the amended IRWA act of 2012, a centralized authority under the aegis of the NCW needs to be created with the authority to receive complaints or grievances regarding any program or advertisement broadcast or publication and investigate/ examine all matters relating to the indecent representation of women. This authority may be headed by Member Secretary, NCW, having representatives from the Advertising Standards Council of India, Press Council of India, ministry of information and broadcasting, and one member having experience of working on women issues. Do you think this is a welcome step and why? 
Appendix 2

\begin{tabular}{|c|c|c|}
\hline S.NO & NAMES & POST \\
\hline 1 & KALINDEE MEHTA & General counsel and Corporate Secretary- SAP Indian Subcontinent \\
\hline 2 & AJAY BHANSAL & Additional Advocate General, Haryana, Supreme Court of India \\
\hline 3 & KARTIK GUPTA & Advocate \\
\hline 4 & RAKHI RUHAL & Assistant Director. UPES \\
\hline 5 & SHIVANI KAPOOR & Advocate \\
\hline 6 & JEETENDRA GUPTA & Advocate-on-record, supreme court of India \\
\hline 7 & KUSHAGRA GUPTA & Fourth year student, Rajiv Gandhi National University of Law, Punjab \\
\hline 8 & ARINDAM BHARADWAJ & Final year law student, Jindal Global Law School, Haryana, Delhi \\
\hline 9 & GOPAL SINGH & $\begin{array}{l}\text { Advocate, Ex. President Municipal Committee, CH. No. 207, } 1^{\text {st }} \text { floor, } \\
\text { Judicial Complex, Bathinda } \\
\text { Punjab and Haryana High court }\end{array}$ \\
\hline 10 & SAUMYA BHARADWAJ & Judicial Magistrate I, Hapur (UP 3232) \\
\hline 11 & VATSALA CHAUHAN & Advocate \& Editor-in-Chief, Corpus Juris: The Law Journal \\
\hline 12 & BRIJESH MEHTA & $\begin{array}{l}\text { Advocate, LAWYERS CHAMBERS, DELHI HIGH COURT, NEW DELHI - } \\
110002\end{array}$ \\
\hline 13 & ASADULLA THANGAL & Associate - AZB \& Partners, Litigation \\
\hline 14 & ABHISHEK KALRA & $\begin{array}{l}\text { Senior Associate - Cyril Amarchand and Mangaldas } \\
\text { Mergers \& Acquisition }\end{array}$ \\
\hline 15 & DAVID RUSSELL & $\begin{array}{l}\text { Senior Manager Legal - Endemol Shine India } \\
\text { Media \& Entertainment }\end{array}$ \\
\hline 16 & JITENDER AGARWAL & Tees Hazari Court, Civil Lawyer \\
\hline 17 & RAJESH CHAUDHARY & Chaudhary and family associates- Saket court- family dispute court \\
\hline 18 & SANJEEV CHAUDHARY & Chaudhary and Associates - High court- senior advocate \\
\hline 19 & DIVYANSH CHAUDHARY & Guliya Associates- Patiyala House- Criminal Lawyer \\
\hline 20 & VIKAS GUPTA & B/A (law), LLB, Additional Advocate General(Punjab) \\
\hline 21 & RAJEEV MITTAL & B/A (law), LLB, High court Chandigarh \\
\hline
\end{tabular}

